\title{
Kemetic Yoga Tourism: A Study of Marketing Strategies in Egypt
}

\author{
By Heba Abdel mohsen abdel kader komeil
}

Yoga tourism has witnessed a consistent development in the recent years. People around the world have become more mindful of health care options which has led to an increase in the quality of wellbeing care as a need in the minds of most age groups today. The worldwide fascination with yoga has inspired many people to travel in order to practise this activity. Kemetic yoga rapidly evolved into the wonder of yoga tourism, which nowadays is a vital and profitable component of the wellness tourism industry. This unique yoga practice draws yoga lovers from across the world, according to an official statement released by the Egyptian tourism minister promoting it internationally. In 2019, Egypt's Ministry of Tourism collaborated with CNN broadcast to produce a short documentary about Kemetic yoga to highlight wellness tourism in the country. Egypt is a unique destination for Kemetic yogis. Although few researchers have studied Kemetic Yoga as an aspect of tourism, this research focused on the examination of marketing strategies that Egypt needs to apply to promote itself as a competitive destination for yoga. Kemetic yoga tourism is a new travel trend in Egypt, promoting a rising touristic attraction and encouraging the potential of further research. This paper focused on the examination of marketing strategies Egypt is currently implementing to promote itself as a viable yoga destination, and to recommend other marketing strategies to promote Kemetic yoga in Egypt. The methodological approach consisted of a constructivist research paradigm, a qualitative methodology and an interview-based data collection method. Intense, semi-formal interviews were conducted with Kemetic yoga practitioners from different experiences and yoga levels who had travelled to Egypt to practice Kemetic yoga.

Keywords: tourism, yoga, medical, health care, wellness, marketing, Kemetic, Egypt

\section{Introduction}

Kemetic yoga tourism is an act in which tourists from all around the world travel to Egypt to obtain salvation and spiritual care in the embrace of ancient Egypt, a place of one of the most interesting and oldest civilizations in the world. The Great Pyramids of Giza, the only surviving ancient wonder, along with ancient Egyptian statues and tombs continue to seize the attention of yogis, while at the same time touring, vacationing, and fully experiencing the attractions of the country. Tourists travel to avail themselves of such facilities because these unique therapies are not available in their own countries. Kemetic yoga is a fast-growing healthcare therapy which tourists are becoming aware of and learning to live a fit lifestyle. This new industry has enormous potential for generating employment

\footnotetext{
"Lecturer, Faculty of Tourism and Hotels, Alexandria University, Egypt.
} 
and earning huge sums of foreign exchange.

The travel industry market for yoga in Egypt is still considered to be underinvestigated; related studies that consider these kinds of tourist activities in advertising settings are practically non-existent. This is combined with a significant absence of research that refers to precise marketing tactics in international tourism (Riege and Perry 2000) which is startling, assuming that replies in this market are so fundamentally critical for arranging worldwide promotion tactics (Tse and Gorn 1993). This study will serve as a pattern for the improvement of more nuanced understandings and theories concerning the promoting of yoga tourism. Additionally, the findings will demonstrate a practical relevance for the Egyptian tourism industry in terms of the development of this market in international contexts.

The findings of the research may be beneficial in improving Egypt's marketing strategies in Kemetic yoga tourism and, subsequently, the marketing performance of the country's yoga tourism industry. Additionally, by conducting this research from a marketing perspective, it provides the opportunity to compare it with other studies on yoga tourists' motivations and the prospect to review expectations on the transferability of knowledge to other aspects of yoga tourism. Accordingly, to fulfill the purpose of the study, the following research questions were addressed:

$>$ How is Egypt currently being promoted as a Kemetic yoga destination?

$>$ What role does authenticity of place play in marketing Kemetic yoga tourism for Egypt?

$>$ What marketing strategies are being used for Kemetic yoga tourism in Egypt?

The structure of the paper is designed as follows. The literature review presents a review of Kemetic yoga, how Egypt has been promoted as a yoga destination and presents a logical model of the essential approaches towards this marketing. The procedure section offers preliminary methodological studies in terms of the chosen constructivist study philosophy, subjective technique, and interview based information collection strategies. The examination and record gathering approaches are laid out, and the inductive data analysis approach is cleared. The findings section represents the vital findings of the research with regard to current marketing approaches. The discussion section then examines the findings from the perspective of marketing Egypt as a Kemetic yoga tourist destination and the linked issues of authenticity of place, spirituality and culture. The summing-up section gives the conclusions from the study and recommendations for future studies. 


\section{Literature Review}

\section{What is Kemetic Yoga?}

Kemetic spirituality, also known as Kemetism, is a reconstruction of ancient Egyptian religion. The title comes from "Kemet," the original, native name for the ancient country of modern-day Egypt.

Kemetic spirituality derives intensely from numerous sources, traditional African spiritual practises, ancient Egyptian architecture and tradition. Together, these form a branch of modern spirituality. Its followers also refer to it as Kemetic Orthodoxy (Krogh and Pillifant 2004). They seek to return to the old Egyptian ways as closely as possible. For some, this includes guidelines on how to worship. For others, however, the religion takes the form of a spiritual tradition.

Though Kemetism represents ancient beliefs, it reinforces contemporary targets. Today, the spiritual foundations set by Ancient Egyptians manifest in various ways, one of the most common is yoga. Interested people can travel to yoga retreats based in Kemetism. Most of the poses in Kemetic yoga look the same, which is especially true of the common human positions. These include child's pose or warrior pose, which because they are natural positions for the human body, gravitate to them without effort (Krogh and Pillifant 2004). Many poses simulate Ancient Egyptian traditions that stem from temple carvings, while others represent specific gods in the Egyptian tradition. Whatever you believe in, the spiritual principles remain available while practising Kemetic yoga (Aggarwal et al. 2008).

Kemetic yoga is a therapeutic and recovering yoga system based on the principles, philosophy, and science of ancient Egypt. Kemetic yoga is characterized by a series of geometrically radical poses and a rule of four breath and tongue connections. The pyramidic power and holy geometry in the Kemetic yoga postures supports the spinal column, helps to correct flaws in the skeletal muscular system to relieve stress and progresses blood circulation, which allows nutrient and oxygen supply to flow more efficiently and richly to vital body systems. By developing nature's application of geometry and physics into yogic forms, Kemetic yogis access higher mindfulness and awaken great spiritual wisdom that encourages them to be grateful for the valuable gift of living in the human body (Hotep 2001). 
History of Kemetic Yoga: The Yoga of Egypt is Much Older than that Found in India

Figure 1. Shu, the Primordial Egyptian God of Light and Air

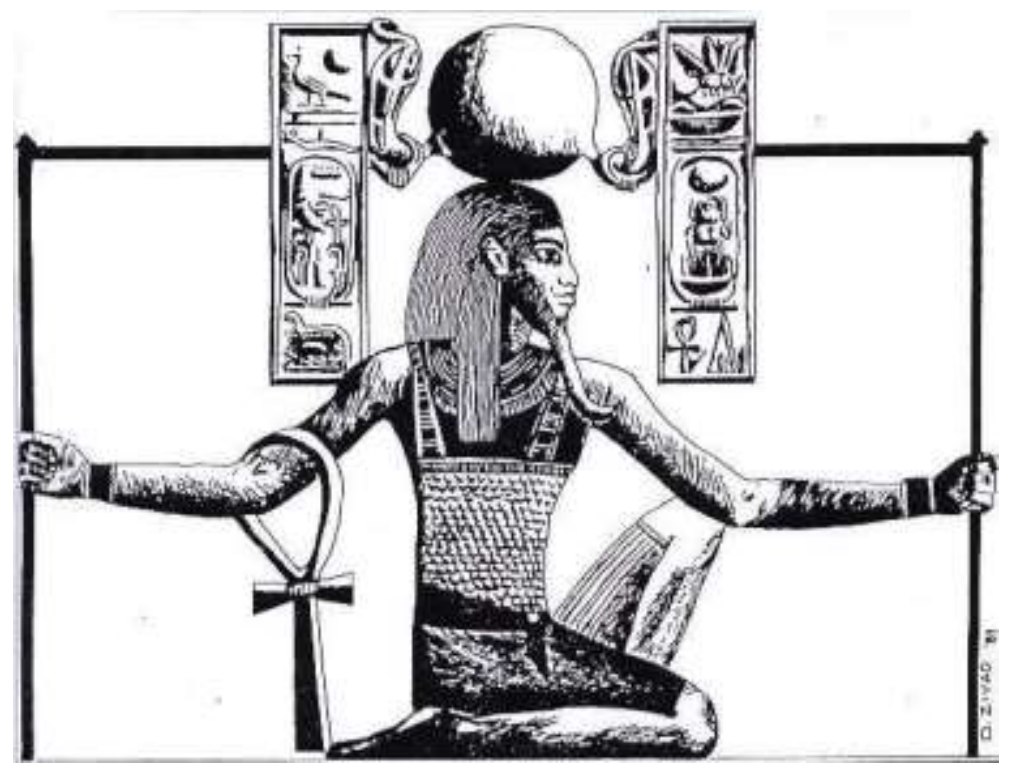

While historians have estimated that yoga stemmed in the Indus Valley around 3,300 BCE, images showing stretching and meditation poses (asanas) which were found in Egypt are thought to have predated this time period. The Kemetic term for the exercise is "Smai Tawi," which means merging the lands of upper Kemet and lower Kemet, and is represented with gods "Heru" and "Sebek" binding ropes around the Smai icon, which illustrates the backbone and lungs. The symbol confirms the "use of breath as the life-power opening the energy along the spine and brain that enlighten" (Shujaa and Shujaa 2015).

The movements in the practice of Kemetic yoga are stated to imitate the poses planned for achieving enlightenment, the highest spiritual level recalled by the neteru (Kemetic deities and nature spirits). The aim of the practice is said to be "attaining divine spiritual wisdom" which is represented by the icon of uraeus (upright Egyptian cobra) coming from the third eye of the pharaoh. As the pharaoh was the leader of the two lands, the symbol can be explained as uniting two human entities, body-mind and soul-spirit, for controlling the life power through the practice of yoga (Scretchen 2020).

Figure 1 was carved on the back of a wooden chair found in the tomb of Pharaoh Tutankhamen is the image of "Shu." Shu $(\mathrm{Su})$ was the ancient Egyptian god of light and air and, as such, personified the wind and the earth's atmosphere. Shu represents the space between the earth and the heavens and gave the breath of life to all living creatures. His long-curved beard indicates that the ancient Egyptians or Kemetic people viewed him as a Netcher or force of nature (Ankh 2007).

Egyptologists who studied ancient Egyptian civilization have known about this carving for thousands of years, yet no one ever equated Shu with yoga. By 
doing a casual examination of his position and the images carved on the chair which incorporates the sun disk at the top of his head and two Cobra snakes, the association with yoga is self-evident. The sun disk on top of his head compares to the crown chakra or vitality centre related to higher insights and enlightenment (Hotep 2001).

The cobras relate to two of the three fundamental Nadis which correspond to yogic skill and are channels through which energy or life force moves, nurtures and accelerates the human body. The position of Shu and all other numerous yoga positions we see signified in ancient Egyptian sculpture and literature are not specific to that culture (Mangesh et al. 2013). The people of ancient Kemet practiced a special style of yoga that originated before the yoga of India, and the training and idea of yoga in India was educated by knowledge that came out of Africa. This is proven by the fact that illustrations of Indian yoga can be found in old Egypt, but illustrations of ancient Kemetic yoga cannot be found in India. The conclusion one can draw from this is that the yoga of Egypt is much older than that found in India (Ankh 2007).

\section{Marketing Egypt as a Kemetic Yoga Destination}

Egypt has all of the ingredients for the perfect yoga destination. Diverse mild weather makes it suitable for the holidays most of the time, as it embraces the vast wealth of historical sights and scenery and modern entertainment in addition to various hotels, making it convenient for yoga tourists. However, there are a number of reasons why Egypt falls short of claiming a share of the wellness tourism industry compared to competing nations such as Jordan, Turkey or the USA. In fact, the Egyptian government provides very little in the way of support compared to official attempts in Turkey and Jordan in the area, and the US internationally, where wellness tourism conferences and associations are encouraged and coordinated to create hundreds of protocols and packages suitable for diverse consumers. More collaboration is needed for Egypt to gain a foothold on the yoga tourism market in the region (Hamdy 2015).

In the review of Egypt's efforts to secure itself as a yoga destination, especially for Kemetic yoga, four different approaches can be identified. Three of these correspond to the positioning of yoga tourism and are based on interpretations of yoga as a wellness, sport or spiritual activity. The country should market Kemetic yoga as an origin of an 'authentic' yoga experience, highlighting the fact that it is the birthplace of this ritual. Thus, by investigating Egypt's unique motivations for yoga tourists, and establishing a better understanding of its marketing strategies for Kemetic yoga tourism, the findings may offer explanation to how other countries, such as the USA, place their own tourism marketing activities.

The marketing of Kemetic yoga as a subset of spirituality and wellness, and to tap into these motivations, appears to have gained great popularity in the international yoga market (Chen et al. 2013). Egypt's marketing activities are often based on presenting the destination as a place where achieving historical and archaeological tourism is easier than anywhere else in the world. Theoretical 
discussion shows that this approach follows a competitor-oriented promotion plan (Riege and Perry 2000) in which strategic efforts have been made to shape a market niche in order to attain a successful market position (Day 1999). Perhaps, the generally understood concept of wellness is integrated in the branding of the so-called 'Egypt experience,' with yoga as an important constituent component (Chen et al. 2013).

This marketing approach is intended as a part of the wellness-related package holidays that usually include spa activities and gourmet food accompanied by the promise of 'royal' treatment provided with modern comforts (Bandyopadhyay and Morais 2005). This is in contrast to the USA yoga market, in which Lehto et al., 2006, found that, "yoga tourists are happy to just visit a sunny place, ideally with a beach or water body around." Hence, it can be suggested that yoga has become a product that is custom made in order to respond to the expectations of its clients, thus incorporating elements of a consumer-oriented marketing strategy that is differentiated by its market target (Day 1999, Gamble and Gilmore 2013).

Another approach of marketing Kemetic yoga in Egypt has been to promote it as greatly valuable to people's health, but not necessarily for any mental or other worldly self-development. Accordingly, yoga is being promoted as a plan to achieve a healthier self with stress on the physical advantages that it can offer (Askegaard and Eckhardt 2012), and shows the general concept of the medicalization of yoga to reveal its simplified presentation as a healing activity. Such an analysis may be more engaging to western tourists who regularly see the activity as part of weight loss, promoting yoga as an effortless alternative to the typical gym experience (Fish 2006). Apparently, such marketing of yoga travel can compare to characteristics of sports tourism, especially since it communicates the physical side of the activity (Telej and Gamble 2019). In Egypt, the utilization of such an approach can be easily observed; it is reflected by disregarding the fact that the activity is a derivative from the Pharaohs' actions, where health and fitness, even if valued, were not the main focus of the practice, interpreting it as a purely physical exercise (Brown et al. 2017).

However, the opposite technique of promoting Egypt as a yoga destination, or more accurately, a spiritual destination, is directed towards people seeking personal awareness and promotional exercises that present Egypt as an unmodernized, exotic place that is "old fashioned or unchanged" (Maddox 2015). This approach of developing images of Egypt as a relic of the past, and ignoring the country's modernisation, aims to target western tourists who desire to escape modern, stressful, hectic lives, and instead, to peaceful, slow-paced destinations (Gan and Frederick 2018).

The sacred land of Egypt provides millions of visitors every year as a place for transformation and opening of the heart, mind, and soul. Egypt offers the elements for Kemetic yogis to explore themselves deeper and find the core of who they truly are. The human backbone provides support, stability and a passageway of energy for the whole body. In the same way, the ancient Egyptians saw the River Nile as the backbone of Egypt. Because of this, they built temples in specific locations along the Nile to activate corresponding chakras (in Indian thought, each of these are centres of spiritual power in the human body, usually considered to be 
seven in number). These temples facilitated the flow of energy for the purification of the human body. In the USA market this spirituality logic has, in recent years, surpassed the generic motivations for yoga tourists, as discussed by Lehto et al. (2006) and now translates into practice through chanting, meditation and reading religious texts to enhance self-awareness and establish a higher level of spirituality.

\section{Authenticity in Kemetic Yoga Tourism Marketing Strategies}

Theorists such as MacCannel (1973) Stated that tourism is a modern quest for authenticity. MacCannel suggests that western tourists are looking for a sense of authenticity that is lacking in their home life; abroad, hosts provide this by creating authentic-seeming presentations of their own culture. In effect, he is suggesting that tourists travel to experience something new that they do not have at home. They may want to learn Salsa in Spain, or watch a traditional child dance show in Cambodia, or may even be as simple as a clean beach and some warm weather that is 'authentically' Spanish (or whichever destination they choose). This type of tourist should be targeted to come to Egypt to practise Kemetic yoga to rejuvenate and cleanse their mind, body and soul in the spiritual plains of Luxor and Aswan, to soak in the heritage of over 3,000 years and embark on a journey of spiritual self-discovery of the soul.

Kemetic yogis visiting Egypt will have the opportunity to be in a sacred space designed for the purposes of spirituality, meditation, and for exploring the ancient mysteries of Egypt. Temples with their columns covered with ancient script serve to stir and encourage the rediscovery of themselves and to illuminate the way to clarification. In contradiction to this, Boorstin (1964) differs by suggesting that modern tourists do not seek authenticity. He suggests that the tourists do not care if the Kemetic yoga lessons are in a yoga studio or in an ancient place.

Kemetic yoga, as a derivative of ancient Egyptian culture, is widely associated with Egypt and at the same time enhances Egypt's image as a yoga destination. Accordingly, practising yoga in Egypt can be identified as an experience branded by greater authenticity than engagement in this exercise anywhere else. This is confirmed by how Lehto et al. (2006) describe the authenticity of the yoga experience as only the secondary push factor for yoga tourism motivations in the USA market, with a much greater emphasis placed on the escapism aspect as the primary push factor. This is also the case in the USA market, in which religious components of the marketing strategy are increasingly excluded in favour of newage spirituality aspects, as part of a shifting emphasis towards fitness and medical logics (Ertimur and Coskuner-Balli 2015). Conversely, the reason for this in the Egypt market might be the absence of a target market fascinated with such an approach that is often considered outmoded and inappropriate to the needs of modern societies (Telej and Gamble 2019).

To conclude the above discussion: the four most popular approaches towards marketing Kemetic yoga as a tourist product of Egypt, identified below, are not only targeting different potential customers, but also correspond to different illustrations of yoga holidays, which is presented in Figure 2. 
Figure 2. Approaches Towards Marketing Egypt as a Yoga Destination

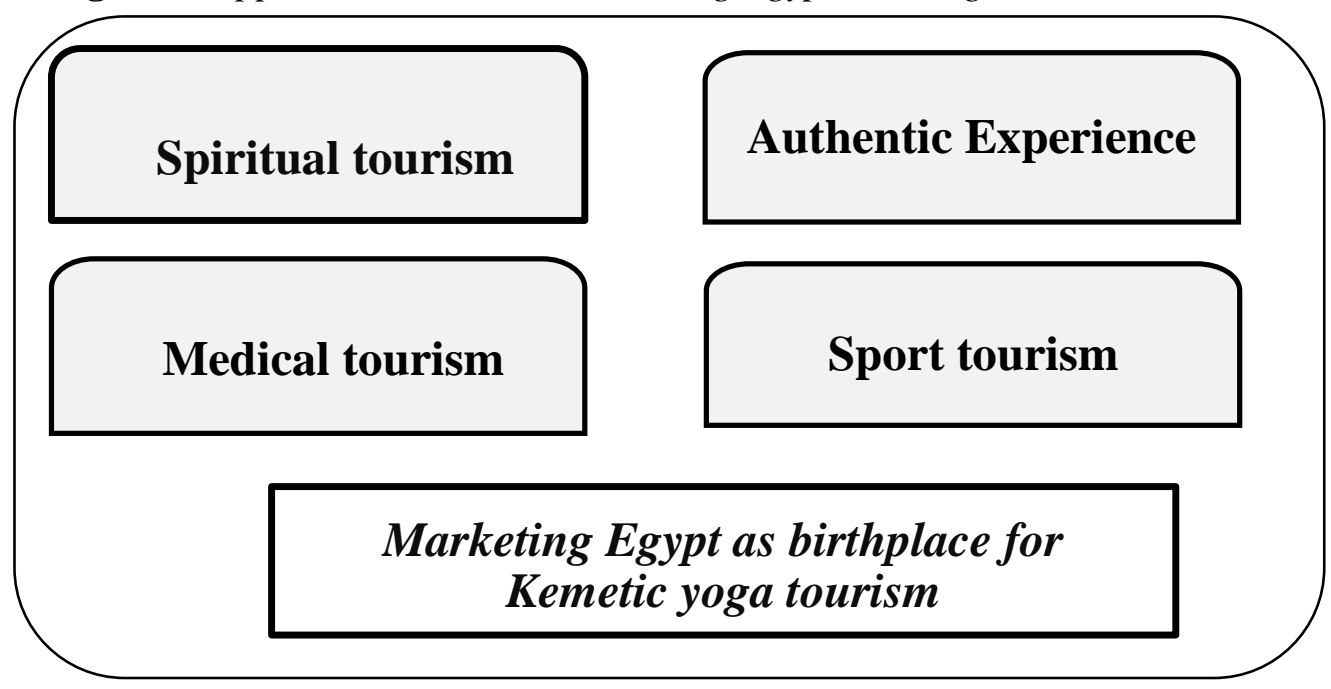

It was noted that the country promotes itself as a yoga destination using various reviews of yoga practice, which correspond to the typologies of yoga tourism and are used to target various demands.

\section{Methodology/Research Philosophy}

This research focuses on the marketing strategies associated with Kemetic yoga tourism; hence, due to the several aspects of this study, utilization of the constructivism paradigm is considered relevant in the investigation of the research questions. Depending on an understanding of "the world of human experience" (Cohen et al. 2013) it has been possible to perceive how the interviewees build their own meanings for the marketing campaigns in which they are experienced.

\section{Qualitative Data Collection}

The core of this study on the constructivism paradigm result in an implementation of the qualitative approach. As this philosophy considers facts as individual concepts, this recommends that persuading the target audience to convey their personal beliefs holds great importance in addressing the research objective of the study. Qualitative research can create a substantial amount of data from a modest sample group (Gratton and Jones 2010). The qualitative strategy is classified by smaller scale studies, permits for a more in-depth investigation, which offers the advantages of allowing the researchers to focus on the course of the information collected, while also gaining a wider understanding of it (Pechlaner and Volgger 2012). Qualitative inquiry, due to its in-depth nature, enabled the author to understand the interviewees' attitudes and emotions, and at the same time to become aware of their perspectives, which are reflections of individualized facts in adherence with constructivism (Ateljevic et al. 2007). Thus, 
the conceptualization of approaches towards Egypt's marketing strategies held by the respondents could be understood.

\section{Sampling Procedure}

The research sample group consisted of non-Egyptian yoga practitioners who had travelled to Egypt for the purpose of Kemetic yoga tourism. These participants were chosen to answer the study's three questions as they each had individual opinions of how Egypt has been promoted as a yoga destination, the types of marketing strategies used and how authentic they found these marketing strategies. The identification of participants for interview-based qualitative research can be realised by using existing contacts, which is the most useful method to access interviewees (Easterby-Smith et al. 2008, Johnson 1975).

The researcher therefore used her personal contacts in the yoga sector to invite yoga practitioners to participate if they had been on a yoga vacation to Egypt. Another sampling technique employed for the purpose of this study was a snowball technique, which was used to supplement the numbers of interviewees (Yin 2011). The utilization of this method can be justified by its usefulness in accruing the requisite quantity of information in situations when obtaining a sufficient number of interviewees appears to be challenging (Blaxter et al. 2006), as was the case in the study due to the limited number of yoga practitioners who had travelled to Egypt for Kemetic yoga tourism purposes. Therefore, the researcher relied on her initial contact of candidates, asking them to forward the invitation to other participants in their yoga class, or other yoga practitioners with whom they were associated.

\section{Online Interview Design}

Semi-structured interviews were especially appropriate for the current study as they gave the researcher the chance to understand different points of view within the context of the three inquires (Cachia and Millward 2011). This strategy further permitted more adaptability due to its less structured nature (Bryman 2015) which gave the interviewer the chance to ask participants to explain, clarify or expand on their responses (Arendt et al. 2012).

\section{Data Collection}

The focus of this paper was to investigate Egypt's marketing strategies that target Kemetic yoga practitioners to visit the destination. Therefore, during the online interviews some personal factual questions were asked, aiming to determine a profile of all respondents. Those data are presented in Table 1. 
Table 1. Profile of Interviewees

\begin{tabular}{|l|c|c|c|c|}
\hline $\mathbf{S}$ & $\begin{array}{c}\text { Age/ } \\
\text { Gender }\end{array}$ & Marital Status & Occupation & Level of progression \\
\hline $\mathrm{A}$ & $48 / \mathrm{F}$ & Divorced & Science Teacher & Advanced \\
\hline $\mathrm{B}$ & $42 / \mathrm{M}$ & Widow & GYM trainer & Advanced \\
\hline $\mathrm{C}$ & $36 / \mathrm{F}$ & Married & Housewife & Intermediate \\
\hline $\mathrm{D}$ & $39 / \mathrm{F}$ & Single & Librarian & Beginner \\
\hline $\mathrm{E}$ & $23 / \mathrm{F}$ & Single & student & Advanced \\
\hline $\mathrm{F}$ & $53 / \mathrm{F}$ & Widow & Flower shop & Intermediate \\
\hline $\mathrm{G}$ & $26 / \mathrm{F}$ & Single & Waitress & Intermediate \\
\hline $\mathrm{H}$ & $33 / \mathrm{F}$ & Married & officer & Beginner \\
\hline $\mathrm{I}$ & $44 / \mathrm{F}$ & Divorced & translator & Advanced \\
\hline $\mathrm{J}$ & $31 / \mathrm{M}$ & Single & Officer & Beginner \\
\hline $\mathrm{K}$ & $30 / \mathrm{F}$ & In relation & Yoga instructor & Advanced \\
\hline $\mathrm{M}$ & $37 / \mathrm{M}$ & ----- & Police officer & Advanced \\
\hline $\mathrm{N}$ & $25 / \mathrm{F}$ & Engaged & IT & Intermediate \\
\hline $\mathrm{O}$ & $38 / \mathrm{F}$ & Divorced & Musician & Beginner \\
\hline $\mathrm{P}$ & $29 / \mathrm{F}$ & ---- & Florist & Beginner \\
\hline $\mathrm{Q}$ & $36 / \mathrm{M}$ & Wisdow & Businessman & Advanced \\
\hline $\mathrm{R}$ & $27 / \mathrm{F}$ & Single & Shop owner & Intermediate \\
\hline $\mathrm{S}$ & $48 / \mathrm{F}$ & Married & Housewife & Beginner \\
\hline
\end{tabular}

Twelve of the initial eighteen people approached agreed to take part in the study. Another six respondents were selected using the snowball technique detailed above, with a total of eighteen yoga practitioners taking part in the interviews. As the researcher looked to relate their points of views to investigate the three inquiry questions, then analyzed for diversity in the sample of interviewees. Therefore, as shown in Table 1, the interviewees varied in different statistical functions. Firstly, the age of the participants extended from 23 to 53 years old. In this research, females are more than males, which made the study not fair in terms of sex. Nevertheless, this may emphasize the concept that women are more dominant than males in practising yoga, (Bankar et al. 2013). Most of the Kemetic yogis varied in terms of profession, and the sample represented diversity in terms of marital status, and level of progression.

All eighteen interviews were conducted in America and were conducted online. The duration of each interview was between 20 and 30 minutes and all of them were digitally recorded. Sample interview questions included: "How do you perceive Egypt as a yoga destination?; Does Egypt have any advantages over other yoga destinations?; How likely are you to recommend land of pharaohs trip to a friend?; Have you come across any marketing activities advertising Egypt as a Kemetic yoga destination? If so, do you think they are successful?" All of the interview recordings were transcribed verbatim in order to prepare for the subsequent analysis of the interview data, as detailed below. 


\section{Data Analysis}

It is suggested that inductive reasoning delivers an easily applied and systematic set of procedures for interpreting qualitative data (Thomas 2006) which can generate reliable and valid findings. Thus, there are several reasons why the inductive approach was selected in adherence with the aim of this study. Initially, as such thinking rejects reference to any grounded suggestions toward the start of the study, while directing the meetings preference was bypassed and the information was interpreted with a new opinion, without contrasting the reactions of the participants with any past examinations. Thus, the primary research began from perception of the individual practices of the interviewees and afterwards it moved from their practices to a broader suggestion about their experiences (Bernard 2011).

This strategy was arguably the most appropriate for this study, particularly because of its innovative and complex nature, it facilitated new perceptions about the relevance of Egypt's promotional activities targeting Kemetic yoga practitioners. Research depended on subjects being built up in the information, as opposed to on any theoretical structures utilized in the study (Creswell 2013, Thomas 2006). This would seemingly convey practical importance for the Egyptian travel industry market, as this would be customer-concentrated and would reflect the newest trends in travelling for Kemetic yoga.

The analysis software NVivo 11 was utilized to code the interview data, as it is recognized as the benchmark computer-aided analysis package for qualitative data analysis (Bazeley and Jackson 2013). Once the numerous data streams from the interviews were inserted into the software as inner sources, they were iteratively evaluated in line with the coding method for the analysis. The data analysis was a non-facing repetitive process of data, "compiling, stripping, reconstructing, understanding and ending," in which the researcher analyzed the copied interview data into codes (Arendt et al. 2012). As a final phase of the study coding technique, consistency analysis was used to cross-note the data against interviewee types (Elo and Kyngäs 2008). This confirmed that the analysis approach was adequate in accomplishing the criteria of the construct for qualitative research reliability developed by Guba (1981).

\section{Results}

The analysis of the interview data showed a wide range of views and insights in relation to key objectives of the study. This section will now present the key findings, with direct quotations from the interviewees.

\section{Spiritual Perspective of Kemetic Yoga Tourism in Egypt}

The observational information confirmed classification of travelling for yoga in categories of sport and spiritual tourism, with aspects of wellness incorporated into both (Chen et al., 2013). In the cases mentioned above, wellbeing is conceived 
in different ways: for (Interviewees B and M) it is linked with activities that are "still mainly physical," while (Interviewees E and Q) interpreted this concept as related to a "highly spiritual practice" nourishing their soul as top priority; "Kemetic yoga allows us to nurture and strengthen the soul, making us all-around more compassionate, kind, and open-minded human beings," "You really feel the heightened spirituality and surrounding energy all around you. The trip was nothing less than heavenly." The contrasts come about from each of the respondents having their own individualized understanding of the world (Bryman 2015), which is fully recognized by a constructivist point of view.

When examining the experimental information, a tendency was noted: longterm yoga practitioners were more likely to perceive their practice as a "spiritual one" than beginners, a fact that may be useful when creating a promotional campaign for Egypt. The findings also settled that some yoga specialists perceive travelling for this activity as a "personalized spiritual journey." Interviewee A said that: "Kemetic yoga understands that self-care is not a trend, but rather a necessary method of ensuring that one can operate to the best of his or her ability." To successfully target these people, Egypt is actively promoting itself as a spiritual destination, so the accord between marketing and motivation can be seen here.

\section{Sport and Wellness Perspective of Kemetic Yoga Tourism in Egypt}

Linking the findings to existing marketing strategies used by Egypt, a certain connection between them was recognized. The image of the country as a yoga destination was built with support on the three categories of tourism - sport, wellness and spiritual - in which it was recognized that yoga belongs. However, the analysis of two of those typologies by Egyptian marketers is slightly superficial. Depending on the primary data, the idea of wellness is much broader than simply relating it to luxurious accommodation and pampering medications, which actually forms a significant part of Egypt's yoga-related tourist promotions.

Based on the Kemetic yoga practitioners' replies from the interviews, aside from spirituality, sports tourism also links with the category of wellness because physical activeness is often perceived as a wellbeing-related area. Such an approach aims to target those who compare the practice with gym activities, from which their main aim is to acquire physical benefits. Interviewee $\mathrm{H}$ commented that, "I like to move and explore the country freely - trying other sports and staying active would be a great experience to my yoga tour." It appears that the perception of a yoga vacation as a wellness-related holiday was the most common, with Interviewee F stating that, "When I started playing Kemetic yoga, I started to play other sports, Kemetic yoga prepares my body for more intense physical exercises." Moreover, it seems that promoting yoga, either as part of wellness holidays, or as an equivalent to gym exercise, reflects some of Kemetic yoga practitioners' understandings of this activity. Two of the respondents perceived the practice as one of those categories, while Interviewee K said that, "Travelling to practice Kemetic yoga is like dedicating a certain amount of effort and time to see that the body does not become a barrier is important." Kemetic yoga prepares the body sufficiently before one goes into more intense forms of meditation, it ensures 
that the body takes it gently and joyfully.

Thus, analyzing data from the replies received it as apparent that the category of wellness tourism should be broadened to incorporate the recreational and sportive dimension of Kemetic yoga tourism.

\section{Educational Perspective of Kemetic Yoga Tourism in Egypt}

None of the marketing approaches implemented by the country appeared to directly target people who want to increase their yoga-related knowledge. This finding was unpredictable, given that Interviewee C stated that, "When I travelled to Egypt, and practised Kemetic yoga in the ancient places, I am now truly enthusiastic about studying yoga, get some answers about its various styles and give them a shot." Interviewee I said, "Kemetic Yoga is more than just poses, and going on retreat, Kemetic can teach you more about the philosophy behind yoga. You'll be given a chance to connect more deeply with yourself through yoga practise and understand more about this ancient art." Perhaps, the strategy that most closely links to this educational search is the promotion of the authenticity of the yoga experience. Interviewee $\mathrm{G}$ mentioned that, "Kemetic yoga is constantly dedicating yourself to a practice, often hitting the mat multiple times a week in order to better understand yoga as a whole. Maybe I read poetry, attend workshops, or watch online videos instructing challenging poses." Instead of the educational aspects of Kemetic yoga, travel appears to be disregarded by Egypt's tourism markets. In fact, it is assumed that yoga is marketed as a component of a travel industry product intended to respond to some wellbeing-related needs of the country's visitors, which does not take into account the more extensive conceptualization of prosperity that mixes different parts of healthy lifestyle.

\section{Social Aspect of Kemetic Yoga Tourism in Egypt}

Examining Egypt's promotion of itself as an attractive Kemetic yoga destination, the aspect of socialization is present in the approach that promotes yoga as a recreation-oriented activity. This strategy is often accompanied by pictures illustrating yoga classes attended by smiling, attractive people. Promoting yoga in this way can be argued to respond to people who are simply searching for "good company" during their yoga holidays. For instance, Interviewee B commented that, "If I go on such type of vacation, I have to be sure that there are great people to spend time with as I am a very social person," and Interviewee P mentioned that, "Travelling in a group to Kemetic yoga retreats gives the chance to meet new people and attract like-minded people, and make new connections and friendships with people who will add positivity to your life."

On the other hand, with regards to marketing Kemetic yoga as spiritual tourism, it is commonly promoted as an activity rehearsed in isolation, most likely intending to feature its intelligent nature. Consequently, the promotion activities do not obviously perceive the link between the desire for spiritual illumination and the need to socialise, which has been built up by analysing the interviewees' reactions. Marketers seem to consider yoga networks in Egypt, neglecting the way 
that they are regularly critical to those looking for spiritual improvement in yoga.

\section{Escapism Aspect of Kemetic Yoga Tourism in Egypt}

Egypt presents itself as a place where yoga can be practiced in a different, more relaxing surrounding than tourists have at any studio. This was important for Interviewee $\mathrm{N}$ who stated, "A reason to travel for Kemetic yoga retreat is to give myself an opportunity to truly relax. Sometimes it is difficult to disconnect and really restore my energy reserves. On a Kemetic yoga retreat, I can really escape and have nothing to do but concentrate on the retreat." Alternatively, it may evoke the interest of people looking for a more metaphysical escapist experience, such as Interviewee R, who said: "In practicing Kemetic yoga, I begin to increase my comfort in dealing only with myself. This comes in handy when traveling solo, and I find myself exploring city streets, mountaintops, and quaint cafés all on my own." Interviewee S said: "Practicing Kemetic yoga in scenic, peaceful surroundings is much more beneficial than doing so at home or in a studio." Hence, we can conclude that, as a yoga destination, Egypt is comprehensively responding to the needs of tourists motivated by the desire to escape, especially to some areas in Egypt like Abydos and Luxor.

\section{Discussion}

To explore the objectives of the study, this section will discuss Kemetic yoga practitioners' opinions of Egypt as a yoga destination. These viewpoints closely associate with the concept of pull motivational factors, which reflect the attractiveness of a specific place (Gnoth 1997). From a marketing point of view, how the destination is seen carries great impact in defining the resources that can be successfully promoted on the tourism market.

Price

The International Economic Forum, one of leading institutions in the field of economic research, issued a report on competitiveness in 2019, citing Egypt as the second cheapest tourist destination in the world. For Kemetic yogis, this assured them that the country is one of the best value destinations to travel in the world. Our findings advance these previous understandings of the role of price in Egypt's yoga tourism by establishing the close connection that exists between the price of services in Egypt and Kemetic yoga-motivated visits to the country. Our findings reveal that the accuracy of Egypt's marketing strategies present Kemetic yoga in Egypt as a native 'competitive product' of the country's culture in order to motivate yoga tourists to visit disregarding the fact of its competitive price.

\section{Egyptian Cuisine}

Egyptian cuisine is quite varied and has a rich history. Vegetables are an 
essential part of traditional Egyptian cuisine, both historically and in modern times. Our data reveal that yoga practitioners consider the correlation between yoga and nutrition, and hence the availability of healthy food as one of the most significant features of Egypt as a yoga destination. We realize that this is attributable to how marketing activities affecting yoga holidaymakers do not place stress on the healthy dining that the destination can offer. This leads us to suggest that Egypt's marketing activities need to highlight the perception of Kemetic yoga in wellbeing terms and should highlight fine dining as a component of a luxurious and pampering wellness holiday. It was also noted that the needs and expectations of yoga holidays greatly depend on how particular individuals interpret this practice, which would constitute an appropriate starting point for any yoga-related marketing strategy.

\section{Create Experiences, not Sightseeing Places}

The tourism industry, which includes the government and private bodies, needs to provide destinations as experiences and not just sightseeing spots alone. Our findings advance these previous understandings of the role of authenticity in Egypt's Kemetic yoga tourism by establishing the close connection that exists between the appreciation of yoga as a derivate of Egyptian culture and yogamotivated visits to the country. The insights from the current study reveal how authenticity of the yoga experience in the Egypt yoga market is also impacted by traditional surroundings where yoga can be practised (such as in the middle of pyramids, temples, or tombs). However, the tactics adopted to respond to this appear to be unrepresentative of what Egypt actually has on offer. This is especially the case with those who would like to experience yoga in its most traditional way but are also seeking enjoyment in their chosen destination.

\section{Sell Niche Tourism Areas as Kemetic Birthplace}

Egypt is currently in a position where it can make a fortune by selling customized experiences like Kemetic yoga tourism. Despite this, the linking of yoga vacations with historical-based cities holidays has not been recognized in our findings as one of the main approaches towards promoting the activity. Instead, we have observed how various marketing strategies targeting yoga tourists incorporate some presentation of history; however, this is only being used to reflect the authenticity of the yoga experience. We now know that historical sites are being treated as a supplement to other marketing activities, while they could in fact form the basis for another more innovative approach to presenting some areas in Egypt as an attractive Kemetic yoga destination.

With too many points of differentiation available, Egyptian tourism should focus on how it has something to offer for everyone, in every category, with all budgets-Egypt on a shoestring, Egypt in luxury, the royal Egypt, urban Egypt, historical Egypt, meditation Egypt and much more. 


\section{Conclusions}

This paper set out to investigate the marketing strategies that Egypt is currently applying to position itself as a competitive yoga destination in the worldwide tourism market. To achieve this purpose, we have examined the relevant academic literature, recognised three original research questions and conducted an in-depth experiential study with yoga practitioners who have travelled to Egypt for Kemetic yoga tourism. As a result of the analysis of the interview data, and the presentation of our key findings and discussion, we now present our conclusions to the three research questions.

The first question asked how Egypt is currently marketed as a Kemetic yoga destination. The findings of this research have prompted the re-situating of yoga tourism in Egypt, utilizing an interesting combinative methodology where a more thorough idea of wellness is compared against an absence of spiritual referring for marketing strategies. The research also emphasises that an understanding of Kemetic yoga tourism is important in deciding the advertising approach adopted by destinations offering yoga retreats. Accordingly, we conclude that marketing activities essentially disregard the flexibility of boundaries between the various categories of tourism to which Kemetic yoga relates. However, our findings demonstrate that this disregards the fact that the concept of wellness can be incorporated in both sport and spiritual activities, which extends beyond the insignificant concept of luxurious holidays (CBI 2016, SRI International 2016). In doing so, the current study suggests new pieces of knowledge into the spirituality aspect of Kemetic yoga, which may serve Egypt yoga tourism regarding repositioning its advertising methodology to the spirituality of yoga wellness tourism (Ertimur and Coskuner-Balli 2015).

The second research question asked what role authenticity plays in Kemetic yoga tourism marketing strategies in Egypt. The detailed evaluation of the country's marketing strategies has advanced prior-related research by identifying four main ways; three of which relate to the understanding of yoga tourism wellness, sport and spiritual tourism - while the fourth is concerned with the authenticity of the yoga experience and its role in marketing. In doing so, we have explained how the motivations of yoga tourists are only partly targeted through a similar strategic marketing approach (Telej and Gamble 2019).

The final research question asked what marketing plans are being used for Kemetic yoga tourism in Egypt. The research revealed how the yoga-related images, mostly associated with the charm of pharaohs, also relates to Egypt's unique heritage and reflects a potential in tourism marketing strategies. Our data analysis shows that additional attractions of a yoga destination are price, natural beauty and aesthetically pleasing food, which are not commonly attributed in the country's marketing strategies, and which do not obviously focus on these aspects. Our findings have also determined that wellness can also refer to sport tourism, which does not appear to be previously included in Egypt's marketing strategies. 


\section{Recommendations}

It is recommended that Egyptian tourism authorities should re-shape their methodology about promoting Kemetic yoga as an attraction. Travel agents should target those looking for an authentic yoga experience and plan a special program for them. It is vital that Egypt's tour operators and agencies targeting those searching for an authentic yoga experience use imagery that is realistic. Presenting the country as a culturally distinct and heritage-rich destination will assuredly evoke the interest of potential visitors. Nevertheless, this should still be a picture of the "real" Egypt without glamorisation. This will mark the promotional attempts as more holistic and trustworthy and more likely to achieve consumer appreciation.

\section{Research Limitations/Implications}

Future research could expand on the sample size and demographics of the research by investigating, possibly through comparative means, larger groups of more diversified yoga lovers from different nations and backgrounds.

\section{References}

Aggarwal A, Guglani M, Goel RK (2008) Spiritual and yoga tourism: a case study on experience of foreign tourists visiting Rishikesh, India. Presented at the Conference on Tourism in India - Challenges Ahead. 15-17 May 2008. IIMK.

Ankh SK (2007) Introduction to Kemetic yoga: the fundamental teachings of mystic integration that were established by 5000-10000 BCE. Edited by S Net. Revised Edition. Kemetic Mysteries Books.

Arendt SW, Roberts KR, Strohbehn C, Ellis J, Paez P, Meyer J (2012) Use of qualitative research in foodservice organizations: a review of challenges, strategies, and applications. International Journal of Contemporary Hospitality Management 24(6): 824-835.

Askegaard S, Eckhardt GM (2012) Global yoga: re-appropriation in the Indian consumptions cape. Marketing Theory 12(1): 50-57.

Ateljevic I, Pritchard A, Morgan N (2007) The critical turn in tourism studies: innovative research methods. Amsterdam: Elsevier.

Bandyopadhyay R, Morais D (2005) Representative dissonance: India's self and western image. Annals of Tourism Research 32(4): 1010-1018.

Bankar MA, Chaudhari SK, Chaudhari KD (2013) Impact of long-term yoga practice on sleep quality and quality of life in the elderly. Journal of Ayurveda and Integrative Medicine 4(1): 20-28.

Bazeley P, Jackson K (2013) Qualitative data analysis with NVivo. 2nd Edition. London: SAGE Publications Limited.

Bernard HR (2011) Research methods in anthropology: qualitative and quantitative approaches. Rowman: Altamira Press.

Blaxter L, Hughes C, Tight M (2006) How to research. Open University Press.

Boorstin D (1964) The image: a guide to pseudo-events in America. New York: Harper.

Brown TC, Miller BM, Adams BM (2017) What's in a name? Group fitness class names and women's reasons for exercising. Health Marketing Quarterly 34(2): 142-155.

Bryman A (2015) Social research methods. 5th Edition. Oxford: Oxford University Press. 
Cachia M, Millward L (2011) The telephone medium and semi-structured interviews: a complementary fit. Qualitative Research in Organizations and Management 6(3): 270-279.

Centre for the Promotion of Imports from developing countries - CBI (2016) Inner wellness tourism from the EU to Asia. CBI.

Chen K, Liu H, Chang F (2013) Essential customer service factors and the segmentation of older visitors within wellness tourism based on hot springs hotels. International Journal of Hospitality Management 35(Dec): 122-132.

Cohen L, Manion L, Morrison K (2013) Research methods in education. 6th Edition. London: Routledge.

Creswell JW (2013) Research design: qualitative, quantitative, and mixed methods approaches. 4th Edition. London: SAGE Publications Limited.

Day GS (1999) Market driven strategy: process for creating value: with a new information. New York: The Free Press.

Easterby-Smith M, Graça M, Antonacopoulou E, Ferdinand J (2008) Absorptive capacity: a process perspective. Management Learning 39(5): 490-505.

Elo S, Kyngäs H (2008) The qualitative content analysis process. Journal of Advanced Nursing 62(1): 107-115.

Ertimur B, Coskuner-Balli G (2015) Navigating the institutional logics of markets: implications for strategic brand management. Journal of Marketing 79(2): 44-57.

Fish A (2006) The commodification and exchange of knowledge in the case of transnational commercial yoga. International Journal of Cultural Property 13(2): 189-206.

Gamble JR, Gilmore A (2013) A new era of consumer marketing? An application of cocreational marketing in the music industry. European Journal of Marketing 47(11/12): 1859 .

Gan LL, Frederick JR (2018) The choice of facilitators in medical tourism. Health Marketing Quarterly 35(1): 70-80.

Gnoth J (1997) Tourism motivation and expectation formation. Annals of Tourism Research 24(2): 283-304.

Gratton C, Jones I (2010) Research methods for sports studies. London: Routledge.

Guba EG (1981) Criteria for assessing the trustworthiness of naturalistic inquiries. Educational Technology Research and Development 29(2): 75-91.

Hamdy A (2015) Egypt country marketing strategy. NP.

Hotep YR (2001) Understanding the yoga skills method and kemeticyoga: melding practice and philosophy. Yoga Skills Productions.

Johnson JM (1975) Doing field research. New York: Free Press.

Krogh MC, Pillifant BA (2004) Kemetic orthodoxy: ancient Egyptian religion on the internet - A research note. Sociology of Religion 65(2): 167-175.

Lehto XY, Brown S, Chen Y, Morrison AM (2006) Yoga tourism as a niche within the wellness tourism market. Tourism Recreation Research 31(1): 25-35.

MacCannell D (1973) Staged authenticity: arrangements of social space in tourist settings. American Sociological Review 79(3): 589-603.

Maddox CB (2015) Studying at the source: Ashtanga yoga tourism and the search for authenticity in Mysore, India. Journal of Tourism and Cultural Change 13(4): 335340.

Mangesh AB, Sarika C, Kiran C, (2013) Impact of long term yoga practice on sleep quality of life in the elderly. Journal of Ayurveda and Integrative Medicine 4(1): 2830.

Pechlaner H, Volgger M (2012) How to promote cooperation in the hospitality industry: generating practitioner-relevant knowledge using the GABEK qualitative research 
strategy. International Journal of Contemporary Hospitality Management 24(6): 925-945.

Riege AM, Perry C (2000) National marketing strategies in international travel and tourism. European Journal of Marketing 34(11/12): 1296-1298.

Scretchen S (2020) Yogapreneur: Yirser Ra Hotep discusses his unique yoga. Black Enterprise.

Shujaa MJ, Shujaa KJ (2015) The SAGE Encyclopedia of African Cultural Heritage in North America. SAGE Publications Inc.

SRI International (2016) Wellness tourism is a growth opportunity worldwide. SRI International.

Telej E, Gamble JR (2019) Yoga wellness tourism: a study of marketing strategies in India. Journal of Consumer Marketing 36(6): 794-805.

Thomas DR (2006) A general inductive approach for analyzing qualitative evaluation data. American Journal of Evaluation 27(2): 230-248.

Tse DK, Gorn GJ (1993) An experiment on the salience of country-of-origin in the era of global brands. Journal of International Marketing 1(1): 57-76.

Yin RK (2011) Qualitative research from start to finish. New York: Guilford Publications. 
